\title{
EL LIGNUM CRUCIS DE LA CATEDRAL DE SEVILLA: NUEVOS DATOS PARA SU INTERPRETACIÓN A LA LUZ DE LOS DOCUMENTOS
}

\author{
POR \\ M. ${ }^{a}$ LUISA MARTÍN ANSÓN \\ U.A.M.
}

La obra conocida como Lignum Crucis de la catedral de Sevilla, una pieza excepcional de la orfebrería de la segunda mitad del siglo XIv, hasta ahora era considerada como una pieza unitaria donada a la catedral en 1389. Del análisis estilístico se infiere que en realidad está formada por tres partes diferentes cuyo ensamblaje, según se deduce de la documentación, es ya un hecho en la primera mitad del siglo xvI.

Palabras clave: Sevilla - Catedral - Trabajos en plata - Siglo XIv.

The exceptional gold and silver work of art known as the Lignum Crucis from Seville Cathedral, dating from the second half of the fourteenth century, has always been considered to be a unitary piece, donated to the cathedral in 1389. Now, however, based on both stylistic analysis and documentation, it can be concluded that it is actually composed of three different parts and that they were joined during the first half of the sixteenth century.

Key word: Seville - Cathedral - silver work - fourteenth century.

A lo largo del siglo XIV en la España cristiana, si exceptuamos la Corona de Aragón donde la orfebrería adquiere gran expansión y altas cotas con el desarrollo de talleres que practicaron las distintas técnicas con maestría, la mayor parte de las veces las piezas conservadas de interés y frecuentemente de notable calidad, son obras de importación. Procedentes en su mayoría de Avignon, Italia y, en menos ocasiones, de la corte parisina, se vinculan básicamente con reyes, miembros de la nobleza y eclesiásticos. Las campañas militares en su caso, la actividad política y los nombramientos como obispos y, muy particularmente, como cardenales, favorecen los viajes al exterior y el conocimiento de manifestaciones artísticas de otros países. Sin duda, esto contribuye a un refinamiento de sus gustos participando de corrientes estéticas diversas. Las reducidas dimensiones y la facilidad de transporte hace que estas obras lleguen a todos los lugares a través de los más variados sistemas y, con frecuencia, sirvan de inspiración para obras de mayor tamaño. Son foco de atracción para el intercambio de obsequios entre los monarcas y objetos codiciados, a veces de devoción particular, para reyes, nobles y gentes de iglesia. Algunos de ellos llegaron a sus destinos actuales bajo la forma de donaciones y otros muchos se perdieron. De éstos, en el mejor de los casos, tenemos constancia por las descripciones de los inventarios. 
Durante esta centuria Castilla cuenta con prelados muy importantes cuya actividad se desarrolla con frecuencia fuera de nuestras fronteras. Prácticamente todos se sintieron atraídos por la manifestaciones artísticas exteriores y fueron poseedores de obras significativas. Entre ellos, a modo de ejemplo, la figura de D. Pedro Gómez Barroso, tío abuelo del Canciller D. Pedro López de Ayala, seducido por la corte avignonense, está indefectiblemente unida al relicario de la Virgen del Cabello ${ }^{1}$. La personalidad de su sobrino y homónimo Pedro Gómez Barroso, que algunos han apodado «el Joven», se interfiere y es difícil deslindar en algunos aspectos de la de otro Pedro en este caso Pedro Gómez de Albornoz, sobrino del cardenal Gil de Albornoz, ambos, prelados de la catedral hispalense y uno de ellos poseedor y donante del relicario que centrará nuestra atención.:

Sobradamente conocidas son las empresas del Cardenal Gil de Albornoz quien entre otras piezas legó a la catedral de Toledo dos estatuillas relicarios de San Eugenio y San Ildefonso tal como refleja su testamento de fecha 29 de Septiembre de 1364, «Item, lego a la iglesia de Toledo las imágenes de San Eugenio y de San Ildefonso, para uso de los altares de San Salvador y de Nuestra Señora, dentro del coro» ${ }^{2}$. Las dos estatuitas de santos llevando relicarios, procedentes de Avignon, ilustran un tipo frecuentemente mencionado en los textos pontificales del siglo $\mathrm{XIV}^{3}$. Asimismo, la catedral de Toledo conserva otra obra maestra, en este caso de la esmaltería sienesa, el llamado relicario de la mano de Santa Lucía, que se supone legado por el Cardenal, puesto que su escudo figura en el pie ${ }^{4}$.

En este ambiente adquiere especial relevancia el Lignum Crucis que centra nuestra atención, obra verdaderamente excepcional en el contexto de la orfebrería europea de la segunda mitad del siglo XIV. Además, por fortuna, contamos con un documento que la describe con minuciosidad aunque, por desgracia, sea difícil conocer la identidad del arzobispo que llevó a cabo la donación al no figurar sus apellidos. Esto indica, por otra parte, que sería un personaje sobradamente conocido en la época y, como es lógico, ha llevado a tratar de identificarle, según su nombre, entre los que ocuparon la sede hispalense por aquellos años.

A pesar de la importancia que esta cuestión tiene y a la que, en su momento, aludiré, atrae toda nuestra atención la belleza y magnífica ejecución de la pieza que se conoce como el Lignum Crucis o la Cruz de oro (Fig. 1), que ha sido citada en numerosas ocasiones pero carece de un análisis en profundidad. En realidad está compuesta de tres piezas distintas integradas e

un único conjunto siendo sus diferencias estilísticas evidentes. En este estudio nos vamos a centrar solamente en la parte superior del conjunto actual, dejando las dos restantes para otra ocasión ya que, como podremos comprobar a la vista de las fuentes documentales, es aquella la donada por el arzobispo D. Pedro. Desconocemos cuando se llevó a cabo el ensamblaje de las tres partes pero, según veremos, en la primera mitad del siglo xvi estaban ya unidas.

Gestoso se ha ocupado de ella en varias publicaciones con interpretación distinta y sólo en

1 Martín Ansón, M.a L., «El Cardenal Don Pedro Gómez Barroso y el relicario de la Virgen del Cabello», Goya, n. ${ }^{\circ}$ 282, 2001, 145-155.

${ }^{2}$ Beneyto-Pérez, J., El Cardenal Albornoz. Hombre de Iglesia y de Estado en Castilla y en Italia, Madrid $1986,298$.

3 Taburet-Delahaye, E., «L'Orfevrerie au poinçon d'Avignon au xvre. siècle», Revue de l'Art, n. ${ }^{\circ}$ 108, $1995,18$.

${ }^{4}$ Idem, «Un reliquaire de Saint Jean Baptiste exécuté par les orfèvres siennois Jacopo di Tondino et Andrea Petrucci pour le cardinal Albornoz», Bollettino d'Arte. Studi di Oreficeria, Supplemento al n. ${ }^{\circ}$ 95, 1996, 123-136.

${ }^{5}$ Gestoso y Pérez, J., Guía artística de Sevilla. Sevilla, 1886, 114-115, dice lo siguiente: Una cruz de oro que en la parte superior y extremos de los brazos laterales contiene magníficos camafeos romanos y esmaltes sencillos en canales verticales y horizontales. Al pie hay unas estatuillas de oro que representan a Cristo cadáver, la Virgen, San Juan y las Marías. La basa contiene 6 lóbulos conopiales y en cada uno un asunto de la vida de Cristo. Notáse a primera vista que éste interesante objeto se halla formado de varios fragmentos: los de la basa son de estilo ojival del siglo XIV; la pieza que sostiene las esculturas conserva muy preciosos esmaltes de época anterior, así como lo es toda la cruz.

AEA, LXXVI, 2003, 301, pp. 23 a 37 
$1886^{5}$ llama la atención sobre la posibilidad de que sean piezas diferentes montadas en una sola. En $1890^{6}$ toma la descripción del documento del Archivo Catedralicio, que más adelante analizaremos, correspondiente a la primera mitad del siglo XVI y añade detrás del nombre del arzobispo Don Pedro su identificación con Gómez Barroso. En la última obra que recogemos suya, donde alude a la citada pieza, en $1915^{7}$, atribuye nuevamente la donación a D. Pedro Gómez Barroso y se lamenta del deterioro sufrido por la misma.

Es curioso que Ceán Bermúdez en $1804^{8}$ en su trabajo sobre la catedral de Sevilla hable sólo de las reliquias, sin aludir detalladamente a los relicarios. Alonso Morgado, en $1906^{9}$, hace referencia a datos, según él, extraídos del Libro de las auténticas de las Reliquias de la Santa Iglesia, atribuyendo la donación a Don Pedro Gómez de Albornoz. Esta información ha sido repetida de forma prácticamente literal en diversas ocasiones ${ }^{10}$. Del mismo modo, Santos y Olivera en $1930^{11}$ la relaciona con D. Pedro Gómez de Albornoz, Arzobispo de Sevilla muerto en 1390.

En 1977 Villar considera la Cruz Relicario del Lignum Crucis una donación del Cardenal Barroso de fines del siglo XIV ${ }^{12}$. Palomero Páramo en $1984^{13}$ atribuye la donación de nuevo a

${ }^{6}$ Idem, Sevilla Monumental y Artística, T, II, Sevilla, 1890 , 424 . La descripción basada en el documento de la primera mitad del siglo xvi dice lo siguiente: Cruz de oro que dio el Arzobispo D. Pedro: Una cruz de oro con su pie de lo mismo con cinco imágenes de bulto de oro que son la una de N. S. descendido de la cruz en los brazos de N.S. ${ }^{\text {y }}$ Joseph de Arimathea e N.S. ${ }^{a}$ - esto no puede ser porque ai dos nuestras Señoras... En nota: esta otra imagen de la Virgen sería quizá la Magdalena- el pie es sexavado y en el hueco de cada sexavo tiene una historia de la Resurrección y en cada historia ay un escudo con una cruz en campo colorado que son las armas del Sr. Arzobispo D. Pedro ( Gómez Barroso) que la dio; las cinco imágenes asientan sobre una tabla de oro y debaxo del Jesu está una planchita de plata por sábana; tiene engastadas 12 piedras de camafeos, zafies, balaxes, topacios y mas tiene en la haz 26 piedras que son zafies balaxes, topacios 5 esmeraldas finas y un crisolito- la sábana tiene enmedio un tornillo de plata que se puede abrir y cerrar.

En los brazos de esta cruz tiene en lo hueco unos viriles en que ay reliquias del Lignum Crucis y de otros diversos santos... y esta reliquia está en una caxa de cuero.

En la última visita de las antiguas de estas Reliquias todas que fue el año 1614 dice que peso esta Reliquia 15 marcos y 4 onças.

7 Idem, «Cruces artísticas de la catedral de Sevilla», Museum, vol. V, 1915, 186, se expresa del siguiente modo: Cruz procesional de mano, de oro con esmaltes translúcidos, donación del arzobispo sevillano D. Pedro Gómez Barroso. Cuando se lee su descripción en los inventarios antiguos de la Catedral produce verdadera pena considerar los atentados de que ha sido objeto comparando lo que fue primitivamente con lo que es en la actualidad. Llaman la atención los 6 camafeos griegos y romanos en que rematan los brazos de la cruz y en los esmaltes translúcidos con bustos de santos pontífices y obispos, únicos que se han salvado y que ocupan los 6 compartimientos en forma como de repisa que sostiene la plataforma en que está el grupo de figuras, las cuales debieron estar también esmaltadas, como cada uno de los 6 espacios en que se halla dividido el pie, el cual contiene varios asuntos religiosos hábilmente cincelados a los que faltan por completo los esmaltes. Tiene de alto $0,52 \times 0,25$.

${ }^{8}$ Ceán Bermúdez, A., Descripción artística de la catedral de Sevilla. Sevilla 1804, 122. Se expresa en los siguientes términos: Son las principales un auténtico Lignum Crucis, una espina de la Corona de Cristo, el cuerpo del mártir San Servando, el del Confesor San Florencio y todas están en custodias, viriles, bustos y cofres de plata de buena forma.

9 Alonso Morgado, J., Prelados sevillanos o Episcopologio de la Santa Iglesia Metropolitana y Patriarcal de Sevilla. Sevilla, 1906, 312. Dice lo siguiente: El Sr. D. Pedro Gómez de Albornoz, Arzobispo de Sevilla, dió en 12 de Julio de 1389 una Cruz con catorce marcos de oro y dos de plata y varias piedras preciosas; un Relicario de plata dorado con dos ángeles y su imagen o figura grabada y varios libros que se expresan al por menor, siendo testigos Don Pedro Manuel, Deán; Don Juan Sánchez, Arcediano de Jerez; y Don Fernan Martinez, Prior y Racionero. En realidad como se puede comprobar los datos corresponden al acta de donación de 1389.

Concluye diciendo que Tiene un Lignum Crucis, y en el pie las Armas del Arzobispado, que son una Cruz y diecíseis aspas en orla.

${ }^{10}$ Ros, C., Los Arzobispos de Sevilla. Luces y sombras en la Sede Hispalense, Sevilla 1986, 76.

Idem. Dir. Historia de la Iglesia de Sevilla, Sevilla 1992, 182.

$"$ Santos y Olivera, B., Guía ilustrada de la Catedral de Sevilla, Madrid 1930, 42. la describe del modo siguiente: Cruz de oro y piedras preciosas, con reliquia del Lignum Crucis y otras. Tiene magníficos camafeos romanos, sencillos esmaltes, zafiros, topacios, etc. con cinco estatuitas de oro que representan el cadáver de Cristo en brazos de Nuestra señora, José de Arimatea y las piadosas mujeres, de estilo ojival. Siglo XIV. Su pie, que es excavado, tiene grabados pasajes de la resurrección, con las armas del donante D, Pedro Gómez de Albornoz, Arzobispo de Sevilla († 1390).

12 Villar Movellán, A., La catedral de Sevilla, Sevilla 1977, 163.

${ }_{13}$ Palomero Páramo, J., «La platería en la catedral de Sevilla», La Catedral de Sevilla, Sevilla, 1984, 587, fig ,n1 567, dice: Relicario del Lignum Crucis con el grupo del Entierro del Cristo. Tesoro de la catedral. Siglo xIV. Fue donado en 1389 a la Catedral por el Cardenal D. Pedro Gómez de Albornoz cuyas armas ostenta. En 1605 fue restaurado por el platero de oro Lázaro Hernández Rincón. 
D. Pedro Gómez de Albornoz y añade que en 1605 fue restaurada por el platero Lázaro Hernández Rincón. Sin embargo respecto a este último dato debe haber una confusión pues Gestoso ${ }^{14}$,que recoge la intervención de este platero, la asigna a otra cruz con reliquias del Lignum Crucis donada por el Sr. Arzobispo D. Pedro y dice al margen que la llevo para adereçarla Lázaro Hernández y que no la buelto. El citado autor se pregunta si no emplearía esta alhaja como otras muchas para realizar una custodia de oro que se le encomendó ${ }^{15}$.

En $1992^{16}$ se define como Lignum Crucis de D. Pedro Gómez de Albornoz. s. XIV. T. Laguna, también en $1992^{17}$, habla de tres piezas legadas por D. Pedro Gómez Albornoz, entre ellas la Cruz relicario del Lignum Crucis. Dice que se carece de datos que indiquen la procedencia de sus artistas, aunque no está exenta de ciertos elementos propios del gótico francés del siglo xIv. En otra obra posterior sólo alude a su donación en 1389 por el cardenal D. Pedro Gómez de Albornoz ${ }^{18}$.

Hasta aquí la historiografía que hemos encontrado, sin incluir algunas otras guías locales. En líneas generales, los autores hacen referencia a ella como parte integrante del tesoro de la catedral sevillana repitiendo con ligeras variantes el contenido de una fuente documental del Archivo catedralicio correspondiente al Inventario de Alhajas. Además, sobre el posible lugar de ejecución de la obra los autores no se pronuncian. Sólo en fechas recientes, y dando por hecho que se trata de una obra unitaria, se ha puesto en relación con elementos propios del gótico francés del siglo XIV.

Sin embargo, consultada la documentación ${ }^{19}$ resulta muy elocuente para aclarar algunos aspectos determinantes, tales como su estado original y el intervalo cronológico en que tuvo lugar el ensamblaje de las tres partes. En realidad contamos con dos documentos básicos y algunas otras referencias. El primero de ellos, fechado el 10 de julio de 1389, en escritura gótica cursiva y latín abreviado ${ }^{20}$, hace referencia a una donación a la catedral de una serie de objetos, en presencia de su notario público y testigos, llevada a cabo por el ... reverendissimus in christo pater et dominus dominus Petrus miseratione Divina archiepiscopus ispalensis, sin precisar su apellido. Su forma de expresión en pasado ... dedit, donavit, cessit, mandauit, transtulit ac irrevocabiliter concessit dicte sue ecclesie ... hace pensar que no se trata de una donación directa sino que certifica una donación inter vivos que en fecha no constatada realizó el arzobispo D. Pedro a la iglesia sevillana. La parte final del mismo lo constata, según se puede apreciar en su traducción ... Yo Guillermo Dodi de San Vicente, clérigo de la diócesis Ebrediniense, notario público por la autoridad apostólica e imperial... con los señores nombrados asistí como testigo personalmente y vi oí que así se hacía, e hice la presente estipulación; por eso, por mandato del citado señor Arzobispo, lo ordené, anoté y publiqué, y, ocupado luego en otros negocios, hice que el presente instrumento/ documento público fuera escrito fielmente por otro y firmando el mismo aquí por mi propia mano lo rehice/redacté de esta forma pública y lo sellé con éste sello mio acostumbrado...

\footnotetext{
${ }^{14}$ Gestoso y Pérez, J., Ensayo de un diccionario de los artífices que florecieron en Sevilla desde el siglo xIII al xvIII inclusive. Sevilla 1900, t. II, 224, recoge la intervención del platero Lázaro Hernández Rincón quien Por libramiento de 30 de Marzo recibió 9.248 mrs. Por el oro y piedras y hechura del adereço de la cruz de oro.

15 Idem, Op. cit., 1890, 424.

${ }^{16}$ Palomero Páramo, J. M., en Magna Hispalensis. El universo de una Iglesia. Sevilla 1992, 535, n. ${ }^{\circ} 257:$ Lignum Crucis de D. Pedro Gómez de Albornoz. S. XIV. Oro con camafeos y piedras preciosas incrustadas en la cruz. Fue donado por el cardenal D. Pedro Gómez de Albornoz, cuyas armas lleva impresas en el pie. Su interés artístico estriba en los camafeos griegos y romanos que rematan los brazos de la cruz y en el espléndido grupo escultórico del Entierro de Cristo, donde la Virgen, San Juan, la Magdalena y José de Arimatea amortajan y lloran el cadáver del Redentor. La fotografía no corresponde a la pieza.

17 Laguna, T., «Orfebrería y artes del metal» en Andalucía, vol. 11 de La España Gótica. Madrid, 1992,94

18 Idem, «La Aljama cristianizada. Memoria de la catedral de Santa María de Sevilla» en Metrópolis Totius Hispaniae. Real Alcázar de Sevilla, 1998-1999, 51

${ }_{19} \mathrm{Mi}$ agradecimiento a Isabel González Ferrin de la Biblioteca Capitular y Colombina por su amabilidad y ayuda.

20 Archivo Catedral Sevilla. Sec. Fondo Histórico General, C.117b N1 22/1. Ver apéndice.
} 
Este arzobispo se ha identificado en unos momentos, entre otros, con D. Pedro Gómez Barroso y con Don Pedro Gómez Albornoz. Por la cronología, según han señalado algunos autores, hay que pensar en el segundo D. Pedro, ya que el anterior parece que había muerto en 1374. Sin embargo, a la vista de la historiografía sobre ambos personajes, se observa que los estudiosos del tema no están de acuerdo sobre quien de los dos fue el primero en ocupar la sede hispalense, mezclándose en ocasiones la biografía de ambos.

Por otra parte, las armas que aparecen en el pie no corresponden ni al arzobispo Gómez Barroso (de gules con cinco leones de plata puestos en sotuer) como supone Gestoso ni al Arzobispado según indicó Morgado. Tampoco se identifican con las que porta D. Pedro Gómez Albornoz (de oro con banda de sinople) como se viene repitiendo insistentemente desde los años treinta. La razón es bastante obvia, ni el cuerpo intermedio ni el pie corresponden a la obra original.

De la lectura detenida del citado documento se deduce que la obra que D. Pedro donó a la catedral atañe únicamente a la cruz relicario y al grupo dispuesto al pie de la misma que, en origen, incluiría una figura más, probablemente la de Nicodemo. Ni el cuerpo intermedio ni el pie actual formaban parte de la obra en origen. Estilísticamente ajena, como veremos, a talleres sevillanos, fue completada en ellos con la incorporación de los camafeos. Para todos, excepto uno de mayor tamaño, fue necesario hacer un marco con variados motivos vegetales. El documento, traducido en su parte más relevante, dice lo siguiente: ... D. Pedro arzobispo de Sevilla por la divina misericordia... dio, donó, cedió, mandó, traspasó y concedió de forma irrevocable a su iglesia ... trasmitió y entregó para siempre sus bienes que a continuación se mencionan, a saber, una cruz grande de oro en la que dice que habia catorce marcos de oro con dos marcos de plata mas o menos y algunas piedras preciosas con su pie de cruz cuadrado, por así decirlo, de oro y con cuatro imágenes también de oro, de Cristo, de la Beata María, de San Juan y de Beata Magdalena, y otras dos imágenes secundarias, pero la altura de la cruz con el pie es aproximadamente de un codo.

A continuación se refiere a un relicario con el escudo del arzobispo que, probablemente, ha sido la causa del error que ha llevado a identificarlo con el escudo del pie del actual Lignum Crucis: ... un relicario de plata dorado con su pie dorado, esmaltado con las armas del mismo Señor Arzobispo y más arriba, en medio del pie, con dos ángeles y con la imagen de dicho Señor Arzobispo elevado sobre las rodillas dobladas y, en la cabeza del mismo relicario, con una caja con su cobertura de berilo a modo de cristal con sus orificios de plata dorados y con un ramo verde colocado por encima y un pelícano con sus hijos de plata dorados.

Después añade a la relación de objetos entregados, muy particularmente libros, las piedras preciosas y camafeos para enriquecer la cruz y precisa que el acabado de ésta y del relicario se pague con sus dones: ... Además unas piedras preciosas que siguen luego para adorno de dicha cruz, a saber cinco camafeos uno grande y cuatro menores, todos bajo la figura de la cabeza sobre calcedonias y siete balajes de peso treinta y siete quilates y dos esmeraldas una pequeña y otra grande de peso cinco quilates y medio y un camafeo en el que esta una figura de hombre ocupando un pequeño campo negro y otras dos piedras de color del balaje y una cornalina. Además cuatro piedras preciosas amatistas...

Sigue con la enumeración de una serie de piedras preciosas y de libros. Tras la descripción de los libros, dice que el mismo Señor Arzobispo da muchos bienes a la misma iglesia y al capítulo confiándoles pleno dominio, propiedad y derechos sobre ellos para el servicio perpetuo de esta Iglesia y de dicho capítulo pero ... prohibida por completo toda enajenación de ellos, de la cruz, del relicario, de las piedras preciosas y de los libros incluso aunque apremie cualquier necesidad o razón para ello, mandando y ordenando de grado que de los dones del mismo Arzobispo y de su mesa episcopal se paguen todos los gastos que quedan aún por ha-

AEA, LXXVI, 2003, 301, pp. 23 a 37 
cer para acabar la cruz y el relicario citado. Es de notar que tanto al comienzo como al final de la donación se insiste con fuerza en que los bienes, a pesar de posibles dificultades, incluso de tipo económico, permanezcan de forma irrevocable en la iglesia.

La personalidad de este D. Pedro arzobispo de Sevilla, según se ha señalado anteriormente, sigue planteando problemas de identificación y de biografía. Su bibliografía es relativamente abundante ya que se le supone el fundador de la Biblioteca Capitular. Si la repasamos someramente podemos observar que se ha identificado con D. Pedro Gómez Barroso, se le ha supuesto primo suyo dándole los apellidos Gómez Álvarez de Albornoz Barroso, se le cita también como Pedro de Toledo, Pedro Gómez de Albornoz y Pedro Gómez Álvarez de Albornoz, se le han asignado dos mandatos, antes y después de su medio hermano D. Fernando, sin aludir a otros supuestos nombres.

Recientemente C. Álvarez no ha dudado a la hora de identificarle como Pedro Gómez Barroso. Para ello se basa en el comentario que fray Martín Sarmiento, bibliófilo del siglo XVIII, hizo, en el convento de San Martín de Madrid, el 4 de septiembre de 1762, al manuscrito $\mathrm{Li}$ ber de visitaçione e consiliaçione medicorum, de Estéfano, uno de los dos médicos personales del arzobispo (el otro era el judeoconverso Juan de Avignon), escrito en 1381, conservado en la B.N.M. En él se lee: De los Barrosos, don Pedro Gómez / Barroso, obispo de Cartagena y cardenal en 1327 / y que murió en 1348, y su pariente o sobrino / don pedro Gómez Barroso, capitán de la Yglesia, / arzobispo de Sevilla y que murió en 1390, que / es nuestro don Pedro... Dice del arzobispo que era natural de Toledo, de casa muy distinguida, debió nacer hacia 1331, vivió fuera de España y en la Curia Romana veinticinco años, fue capitán en la Marca d'Ancona... llegó al arzobispado de Sevilla en $1379^{21}$. A él corresponderían dos donaciones inter vivos al Cabildo de la Iglesia Catedral; una de 121 volúmenes el 27 de junio de $1387^{22}$ y otra, la que venimos analizando, de 10 de julio de 1389, de una cruz de oro con piedras preciosas, un relicario de San Leandro y nueve libros más ${ }^{23}$. Por otra parte, al dorso del citado documento hay tres anotaciones y sólo en la que por letra corresponde a los siglos XVII-XVIII se da el nombre completo de D. Pedro Gómez Barroso ${ }^{24}$. Posiblemente esta haya sido en el pasado la causa de la identificación y atribución.

Habitualmente, cuando sólo se da a conocer el nombre, significa que el personaje era sobradamente conocido, pero aquí nos encontramos con dos personalidades de gran entidad que, sucesivamente, ocuparon la sede hispalense en un marco cronológico muy estrecho, ambos con el mismo nombre. Sin pretender entrar en la polémica, la actividad desarrollada tanto por D. Pedro Gómez de Albornoz quien, al igual que su hermanastro y también arzobispo de Sevilla acompañó a su tío el cardenal Gil de Albornoz a Italia ${ }^{25}$, como la de D .Pedro Gómez Barroso,

21 Álvarez Márquez, C., Op. cit., 1999, 11-13. Nota 21, 19... e a onrra e //a loor del beatissimo reueren //dissimo padre señor don Pedro // natural de la honorantíssima çibdat de Toledo, casa antigua de // mucha buena sabidoría, arçobispo / I de la muy noble perfectíssima çib// dat de Seuilla, en la era del Señor de mille e trezientos e ochenta e vn año, ordeno e fag/lo este libro, segunt el señor// arçobispo mandó...

${ }^{22}$ Idem, «La Biblioteca Capitular de la Catedral hispalense en el siglo xv», Archivo Hispalense, 1987, 3, 11-31.

${ }_{23}$ Ver documento relativo a la nota $n .^{\circ} 20$, en el apéndice .

${ }^{24}$ En gótica cursiva de fines del siglo xiv: Donaçión de la cruz de oro e de las piedras para ella/l e del reliquario de Sant Leandre e de algunos libros// de los que están en la librería <la> qual donaçión fisol/ el arçobispo don Pedro, de la buena memoria. Anno Domini 1 V CCCLXXXIX.

En gótica textual de fines del siglo XIV: Donaçión que fizo el arçobispo don Pedro, de// buena memoria, a esta Santa Yglesia de la cruz de oro y del reliquario de San Leandre con munchas piedras// preciosas y de mu <cho $>$ valor y de munchos libros que// están en la librería en 10 de julio, año 1389, ante Guillermo Dodi, notario.

Escritura de los siglos XVII-XVIII; Donazión que hizo el señor arzobis// po don Pedro Gómez Barroso de santal/ memoria a esta santa yglesia de la cruz// de oro y del relicario de San Leandro// con muchas piedras presiosas y de // mucho valor y de muchos libros quel/ están en la librería. Su fecha en Seuilla,// en 10 de jullio de 1389 años, antel/ Guillermo Dodi, notario.

${ }_{25}$ Ver: Beneyto Pérez, J., Op. cit. Madrid 1986, 54. A su vuelta a los Estados Pontificios después de que Urbano V le hubiera pedido en 1365 que aceptara como legado suyo, deja en Nápoles a su sobrino Fernando Gómez de Albornoz.

AEA, LXXVI, 2003, 301, pp. 23 a 37 
que ocupo un papel destacado en la corte y fuera de ella, pudieron propiciar los legados. Lo cierto es que, ateniéndonos a la documentación, ignoramos sus apellidos ${ }^{26}$. Dejamos esta cuestión para los especialistas pues no afecta directamente al estudio de la pieza que presentamos.

El segundo documento en que se describe la obra que nos ocupa, sin fecha, pero que se puede situar en la primera mitad del siglo xvi, es el que, sin duda, ha servido de base a la historiografía citada, pues son fácilmente constatables algunos de sus párrafos en los anteriormente referenciados por ejemplo de la obra de Gestoso. El primer dato que extraemos de éste documento es que por entonces la pieza está ya formada por las tres partes actuales y se describe de forma precisa ${ }^{27}$. Mediante las anotaciones de las sucesivas visitas efectuadas en 1558, 1563$1565,1575,1595,1600$, se ve el deterioro progresivo subrayado por la perdida de piedras y la disminución en el peso. Entre alguna otra referencia encontrada sabemos que Una cruz de oro con cinco figuras de oro: sacala el dia uno en la Prozesion de la Cruz de Mayo ${ }^{28}$.

Ahora bien, si observamos detenidamente el Lignum Crucis y contrastamos la información de ambos documentos, podemos extraer una serie de conclusiones importantes. En primer lugar, la precisión espléndida del de 1389 en su descripción. La altura actual del relicario es de $54 \mathrm{~cm}$. Considerando que en origen estaba formado por la cruz y el grupo escultórico y que las otras dos piezas son de procedencia distinta, la altura es de $39 \mathrm{~cm}$., más o menos un codo (42

Mollat, G., Les Papes d'Avignon 1305-1378. Paris 1949, 237, entre las órdenes vejatorias de Urbano V hacia Gil de Albornoz habla de la destitución de su sobrino, Gómez Albornoz que no había desmerecido como rector de Bolonia pero que sin duda inspiraba el recelo de Bernabo Visconti. Seguramente se refiere a Fernando. Su biografía la conocemos con cierta fiabilidad: Russell, P.E., «The Memorias of Fernan Alvarez de Albornoz, Archbishop of Seville, 1371-1380», Hispanic Studies in honour of I. Gonzalez Llubera, Oxford 1959, 320-330. Las Crónicas no son aclaratorias en este sentido. En la Crónica de Enrique II, Rosell, C. Crónicas de los Reyes de Castilla, T.II, LXVIII, Madrid, 1953, 28 y 58, en el año de 1375 al hablar de las bodas de sus hijos durante los meses de mayo y junio en Soria, dice: En esta cibdad de Soria, estando y el Rey D. Enrique, vino y a le ver Micer Gómez de Albornoz, sobrino del Cardenal Don Gil de Albornoz, que era Senador de Roma, e Juez de las apelaciones della, é Duque de Tusculi, é Conde de Asculi, é Marques de la Marca de Ancona. E vino en gran estado, que traia seiscientas cavalgaduras, e mucha vaxilla de oro, é de plata, é joyas, é divisas; é despues que salio de Castilla murió a pocos dias. Hay que recordar que Fernando es arzobispo de Sevilla de 1371 a 1377 y aqui no dice que sea obispo hispalense. Si se refiere a Pedro dice que murió a los pocos días, lo que tampoco parece exacto. En las Adiciones a las Notas de la Crónica del Rey D. Enrique II, el año de 1372 se cita un Petrus Gometij, que se ha identificado con Pedro Gómez Barroso, como Archiepiscopus Hipalensis.

${ }^{26}$ Respecto a la posible identidad de los arzobispos, ver entre otras obras:

Aldea Vaquero, Q., Dir., Diccionario de Historia Eclesiástica de España, Madrid 1972, vol. I, 1026.

Alonso Morgado, J., Op. cit., 305-313.

Álvarez Márquez, C., Op. cit., 1987 y Op. cit., 1999.

Beltrán de Heredia, V., Cartulario de la Universidad de Salamanca (1218-1600), Salamanca 1970, 158.

Eubel, C., Hierarchia Catholica Medii Aevi sive Summorum Pontificum, S.R.E. Cardenalium Ecclesiarum Artittitum

Serie ab anno 1198 usque ad annum 1431 perducta. Monasterii MDCCCCXIII, 168.

Gams, P. B., Series Episcoporum Ecclesiae Catholicae Ratisbonae 1873-86. Hispania, 73.

Guillemain, B., La Cour Pontificale d'Avignon (1309-1376). Paris 1962, 269, nota 461.

Ladero Quesada, M.A., La ciudad medieval. Historia de Sevilla, Sevilla 1980, vol. II, 2." ed., 200.

Minguella, T., Historia de la Diócesis de Sigüenza y de sus Obispos. Madrid, 1912, vol. II, 58-66.

Morgado, A. de, Historia de Sevilla en la cual se contienen sus antigüedades, grandezas y cosas memorables en ella acontecidas desde su fundación hasta nuestros tiempos. Sevilla 1587, 302.

Ortiz de Zúñiga, D., Anales eclesiásticos y seculares de la muy noble y muy leal ciudad de Sevilla, Madrid 1795, Ed. Sevilla 1988, t. II, 185-193, 193-205, 211-232.

Ros, C., Op. cit., 1986, 75-76. Op. cit., 1992, 181.

Rosell, C., Crónicas de los Reyes de Castilla. Madrid 1953, Cap. IX, 464; Cap. XIX, 468.

Rubio Álvarez, F., «Don Pedro Gómez Barroso, Arzobispo de Sevilla, y su Catecismo en Romance Castellano», Archivo Hispalense, $1957, \mathrm{n}^{\circ}{ }^{86}, 129-146$.

Sánchez Herrero, J., «La iglesia andaluza en la Baja Edad Media siglos XIII al XV», Actas del I Coloquio de Historia de Andalucía. Córdoba, 1982, 285.

«Los obispos castellanos, su actividad académica y cultural durante el siglo xIv, 1316-1377» en Pensamiento Medieval Hispano, Madrid 1998, vol. I, 261-262.

${ }^{27}$ Titulo delas reliquias $q(\mathrm{ue})$ estan enla sacristia $n 1$ pr(imer). Biblioteca Capitular y Colombina. Sevilla A.C.S. Secc. Fábrica. Lib. 397, fol. 2r-2v. Ver apéndice.

${ }^{28}$ Biblioteca Capitular y Colombina, sig. 59-4-4, p. 92.

$A E A$, LXXVI, 2003, 301, pp. 23 a 37 
$\mathrm{cm}$.), medida establecida. Esos centímetros de diferencia podrían corresponder al pie de cruz cuadrado, por asi decirlo, probablemente una pequeña plataforma rectangular, de la que quedaría una fina lámina visible sobre la actual ménsula en la que apoya. En ella irían colocadas las seis imágenes citadas, tres a cada lado de la cruz, manteniendo un lógico equilibrio. En el segundo documento, correspondiente a la primera mitad del siglo XVI, donde ya la pieza se describe en su montaje actual, podemos observar que el número de imágenes se ha reducido a cinco, tal vez para adaptarse al perfil de la nueva base. Además, es evidente que las figuras de la Magdalena y José de Arimatea se ubican en un reducido espacio. Por tanto, el ensamblaje se produjo entre ambas fechas (Fig. 2).

Centrándonos ahora en el análisis estilístico, vemos que la cruz, bastante deteriorada, lleva decoración por ambas caras. En los extremos de los brazos añade unos apéndices circulares con sendos camafeos, los seis referenciados ya en el primer documento. Cinco de ellos presentan cabezas y en el otro destaca la figura de un putti alado sobre campo negro. Son de tamaños diferentes por lo que se insertan en unas cápsulas decoradas con forma estrellada y rosetas o con motivos vegetales de diversos tipos de hojas. A estas monturas se refiere, sin duda, el documento cuando dice que se paguen los gastos que quedan aún por hacer para acabar la cruz y, seguramente, fueron ejecutadas en talleres sevillanos.

La cruz presenta estructura poligonal marcando sus lados mediante aristas. Las caras principales están cubiertas con decoración vegetal. En el anverso, se forma a base de tallos ondulantes acabados en hojas trilobuladas sobre fondo azul, dentro de un esquema oval y, en los espacios intermedios, pequeñas hojas destacan sobre fondo rojo. En el reverso, el crecimiento vegetal es orgánico sobre fondo azul. Encima de esta ornamentación se colocan una serie de piedras sujetas mediante uñas, algunas han desaparecido. En el centro se reserva un espacio cruciforme y en los brazos sendos huecos ovales a modo de viriles para la visión de la reliquia.

Al pie de la cruz se sitúa el magnífico grupo de esculturas que dan vida a uno de los episodios más dramáticos y como tal se plasma, la Lamentación sobre el cuerpo de Cristo muerto (Fig. 3). La Virgen, desplazada hacia un lateral, está sentada y sostiene sobre sus rodillas la parte superior del cuerpo de su Hijo que, inerte, yace en el suelo. Cubre su cabeza con una toca y su rostro avejentado refleja un inmenso dolor. Su cara de formas redondeadas, la dramática animación, el sutil tratamiento de las superficies etc. recuerda, salvando las distancias temáticas, a la sirvienta del grupo realizado en mármol con el tema de la Presentación en el templo, en el Museo de Cluny, fechable hacia 1370-80 (Fig. 4). Sin entrar en la polémica de su atribución a André Beauneveu, a Jean de Liège o algún otro escultor importante del entorno de Carlos $\mathrm{V}^{29}$, se puede decir que está patente esa vinculación con el estilo del valle del Mosa que, en el caso del grupo escénico de Sevilla se ratifica por otras características propias del trabajo del metal.

La figura de Cristo traduce perfectamente la rigidez de la muerte. Los brazos caen a lo largo del cuerpo, los miembros se dislocan. El abdomen se hunde y las costillas sobresalen mientras el vientre se hincha. El rostro destrozado, de nariz recta, con pómulos salientes y boca entreabierta, refleja las huellas de la pasión. El cabello lacio y la barba puntiaguda acentúan esa sensación. Trae a la memoria obras como el Cristo de madera de la catedral de San Juan de Perpiñan. A sus pies, María Magdalena, de rodillas, en actitud expectante, con los brazos adelantados. Su larguísimo cabello cae confundiendose con los suaves plegados de su vestido

${ }^{29}$ Ver entre otros: Schmidt, G., «Beiträge zu Stil und Oeuvre des Jean de Liège», Metropolitan Museum Journal, 4 , 1971, 81-105.

Ostoia, V. K., «Contributions on the Style and Works of Jean de Liège», Metropolitan Museum Journal, 4, 1971, 106107.

Erlande-Brandenburg, A., Musée du Cluny. Guide. Paris, 1989, 76.

Idem, Musée National du Moyen Age. Thermes du Cluny. Paris, 1993, 141-142.

AEA, LXXVI, 2003, 301, pp. 23 a 37 

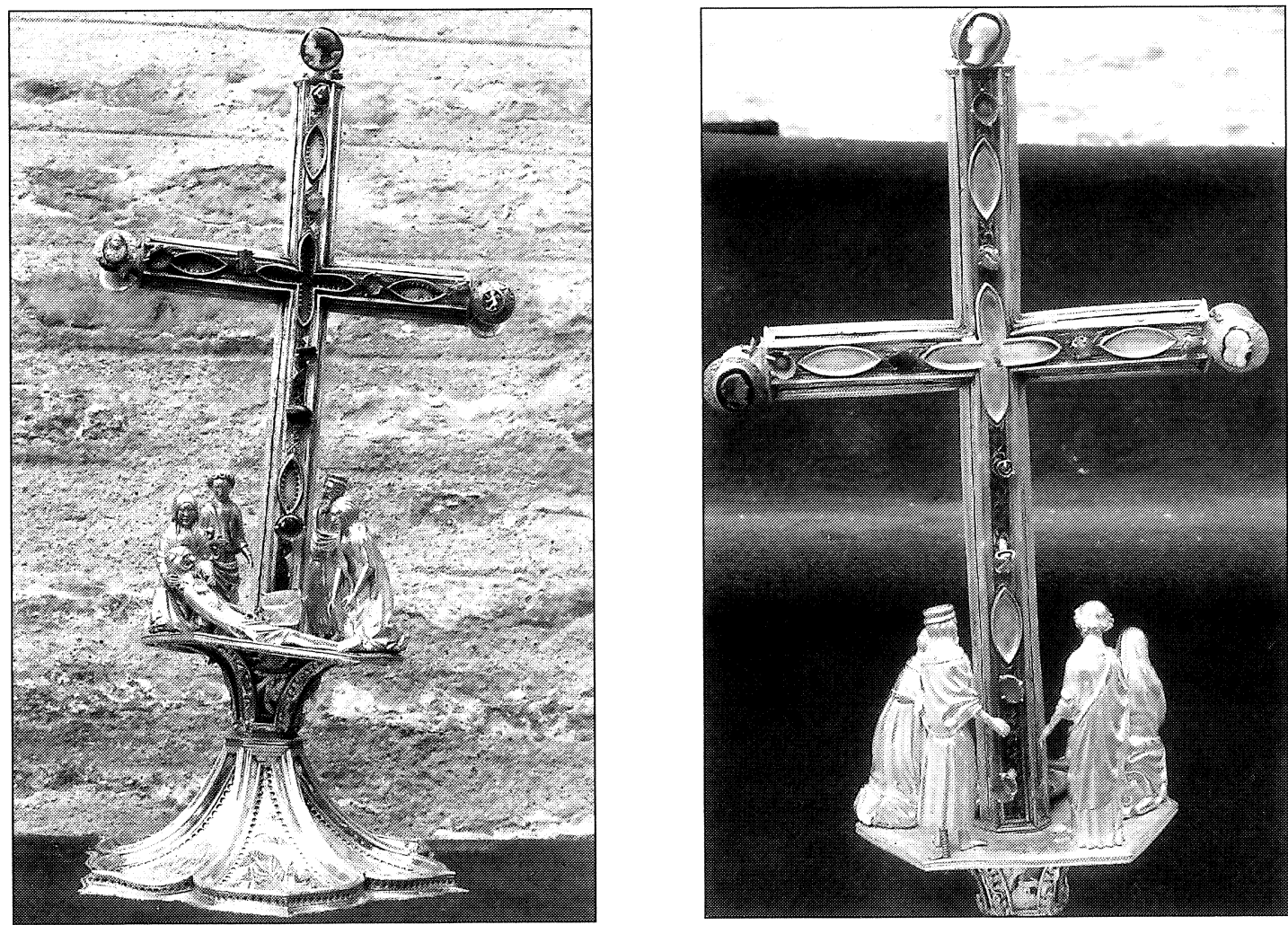

1

3

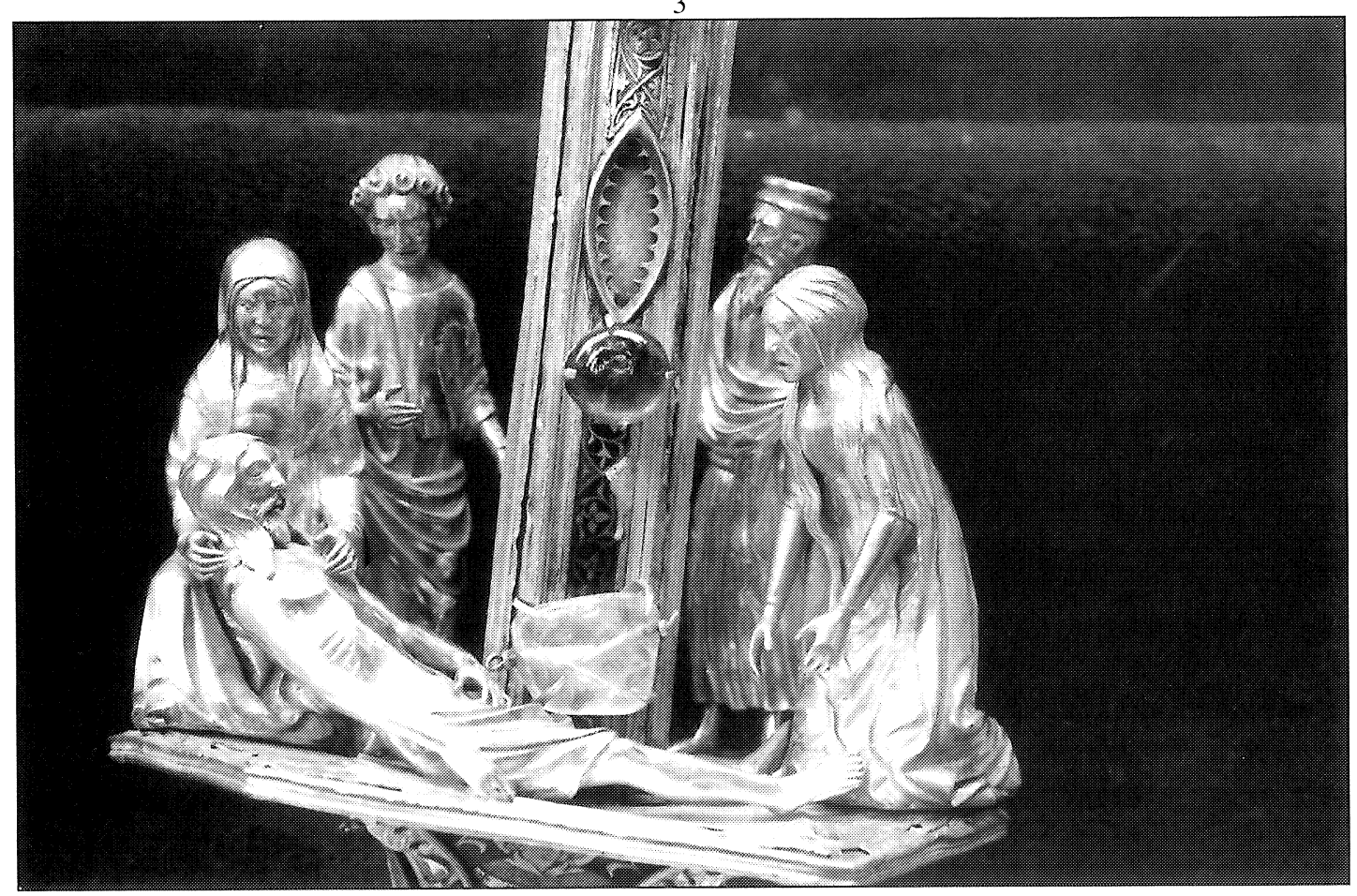

Fig. 1. Lignum Crucis. Catedral de Sevilla. Mediados del s. XIV.

Fig. 2. Lignum Crucis. Catedral de Sevilla. Parte posterior.

Fig. 3. Lignum Crucis. Catedral de Sevilla. Detalle.

AEA, LXXVI, 2003, 301, pp. 23 a 37 
y las huellas del dolor son visibles en su rostro. Detrás de ella se ubica José de Arimatea con tocado y larga barba de anciano. A su lado, seguramente, se encontraba Nicodemo. Estas dos figuras son con toda probabilidad a las que el documento alude como secundarias. El grupo se completa con la imagen de San Juan vestido con túnica y manto y un tipo de peinado en el que el cabello se pega al cráneo formando una corona de bucles circulares alrededor. Este modelo aparece ya en la primera mitad del siglo XIII.

La escena se inscribe dentro de un realismo y expresividad propios de las mejores obras de la producción artística de la Europa del Norte. En 1300 un maestro germánico había dado forma plástica a la lamentación impetuosa de la Virgen sosteniendo el cuerpo muerto de Cristo, la Vesperbild, (imagen de vísperas) cuyo nombre se remonta a la costumbre de recordar el Viernes Santo, en el tiempo litúrgico de las vísperas —entre la muerte en la cruz y el entierro- las llagas de Cristo que yace muerto en el regazo de su madre. El tema conocerá su mayor expansión en tierras germánicas desde 1330. La nueva sensibilidad se muestra en el Imperio en una producción sin equivalente en el resto de Europa. Se basa en una nueva visión de las relaciones entre Dios y el alma humana derivada de los textos de los místicos del fin del medievo. La literatura en primer lugar y la escultura después, se harán eco de ello. Personalidades como las de Eckhart, Jean Tauler, Henri Suso y Jean Ruysbroek contribuyen a difundir estas ideas.

El cuerpo de Jesús en el suelo, con la cabeza reclinada sobre las rodillas de la Virgen, responde a la actitud descrita en las Meditationes vitae Christi relacionadas con S. Buenaventura y atribuidas al franciscano Giovanni de Caulibus de San Gimignano, compuestas a principios del siglo XIV. Mientras los evangelios iban dirigidos al intelecto, las Meditaciones lo eran al corazón. El texto es especialmente claro en la evocación y representación del dolor de la Virgen, no sólo al pie de la cruz sino también en el momento en que Cristo es descendido de ella. Su Officium de compassione B. Mariae Virginis ofrece una poética representación de la contemplación, de la Compassio, de la Virgen sobre el cuerpo muerto de su Hijo. Este acento lírico domina los dramas de la Pasión, el arte y la literatura. Será la fórmula preferida al final de la Edad Media ${ }^{30}$. Seguramente la presencia de esta obra en la catedral de Sevilla influyó en el desarrollo del tema en el arte hispalense a través de una obra de importación que viene a sumarse a las ya analizadas en otras ocasiones ${ }^{31}$. Las figuras en bulto redondo constituyen un auténtico grupo escultórico que trae a la memoria la representación teatral, anticipándose a los grandes conjuntos, como por ejemplo la Puesta en el Sepulcro de la Colegial de Sain-Vincent, Soignies (1440-1450), la del Hospital de Tonnerre (1453) o la de la Abadía de Solesmes, atribuida a Michel Colombe (1496) entre otros. El ciclo dramático de la Pasión, surgido en Italia en el siglo XII, se desarrolla en Francia a fines de la centuria siguiente. Este grupo seguramente forma parte de la interpretación del Planctus Litúrgico, composición cuyo contenido se basa en la expresión de los sentimientos de los personajes que asistieron a la crucifixión, especialmente de la Virgen, por lo que se conoce como Planctus Mariae. El Planctus debe ser considerado como una composición lírica que puede usarse para intensificar la emoción y el drama de la Crucifixión o puede coexistir con el drama de la Pasión - forma narrativa - como un tipo de lírica distinto y autónomo. No parece probable que los dramas deriven del Planctus ${ }^{32}$.

Sin duda, los opúsculos de dos autores anónimos, el Pseudo-Anselmo con su Dialogus Mariae et Anselmi de Passione Domini y el Pseudo-Bernardo con su Liber de Passione Christi

\footnotetext{
${ }^{30}$ Trens, M., El arte en la Pasión de Nuestro Señor siglos XIII-XvilI, Barcelona 1945, 47.

31 Gabardón de la Banda, J. F., «Los grupos escultóricos bajomedievales de la Piedad en la Archidiócesis hispalense», Laboratorio de Arte, n. ${ }^{\circ}$ 10, 1997, 391-401.

${ }^{32}$ Sticca, S., The Planctus Mariae in the dramatic tradition of the Middle Ages (1931), Ed. University of Georgia Press, $1988,126$.
}

$A E A$, LXXVI, 2003, 301, pp. 23 a 37 
et doloribus et planctibus Matris ejus contribuyeron ampliamente a extender entre los cristianos un tema fundamental en la Edad Media. Fueron además la base de numerosos autores posteriores ${ }^{33}$.

En el ámbito de la interpretación, de todos los oficios litúrgicos éste sin duda debió ser el más estático, disponiendo las figuras con una especie de movimiento congelado, capaz de transmitir el desfallecimiento de sus protagonistas a causa del dolor, como en un cuadro viviente. Este lamento lírico era aceptado por la liturgia romana del Viernes Santo que permitía que en un momento dado de los Oficios del día, normalmente al final de los Maítines, se pudiera entonar, jugando papel protagonista la música. Para ello se disponían plataformas a modo de escenario en el interior de las catedrales ${ }^{34}$.

Otras representaciones teatrales en orfebrería, a veces en el interior de micro-arquitecturas abiertas, podríamos citar, correspondientes a diversos momentos cronológicos.

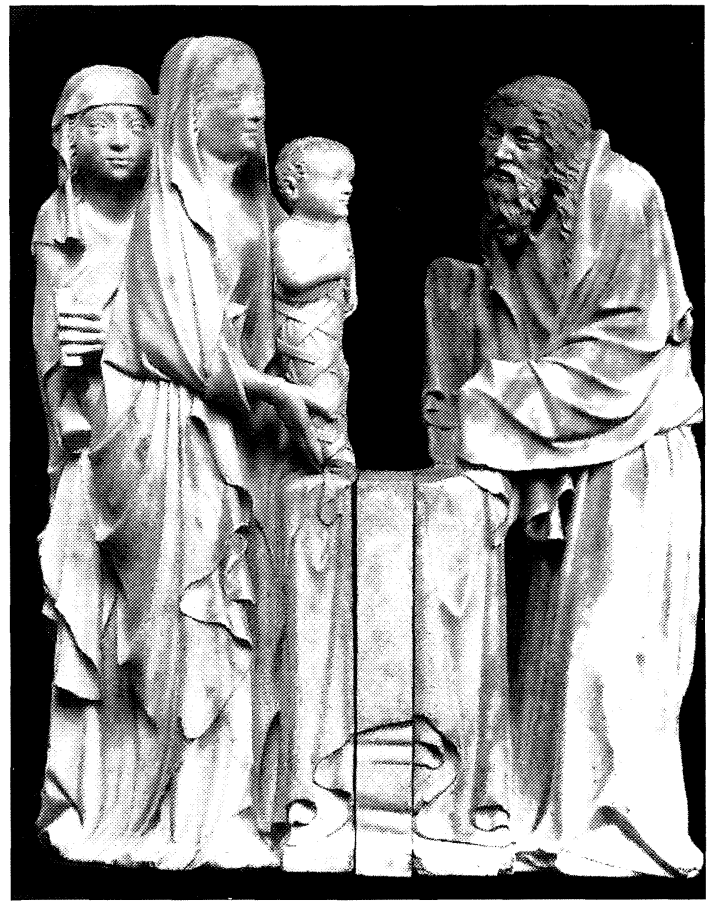

Fig. 4. Grupo de la Presentación en el templo. Museo de Cluny. Sin duda, una de las mas importantes la constituye el Relicario-Capilla del Santo Sepulcro (Catedral de Pamplona), hacia 1285-90, con puesta en escena de la Visitatio Sepulcri, las Santas Mujeres en el sepulcro en un espacio auténtico del drama de la mañana de Pascua ${ }^{35}$. Un episodio de la infancia de Cristo es el que interpretan las figuritas en la Huida a Egipto de dos grupos conservados. En uno de ellos (Tesoro de la Catedral de Savona, fig. 5), los actores si sitúan en una plataforma rectangular mientras el otro grupo (Tesoro de la iglesia de SS. Annunziata, Gaeta, fig. 6) está burdamente asentado sobre el pie de una cruz o de un relicario ${ }^{36}$. La tendencia a formar grupos a partir de estatuas independientes es aparentemente una invención parisína y tiene gran éxito en toda Europa occidental. Surgen desde mitad del siglo xIII con carácter monumental probablemente en relación con la escultura catedralicia apareciendo también en el marfil y perviven durante mucho tiempo El orfebre rivaliza con el escultor al estar trabajadas las figuras completamente en bulto redondo.

Entre los distintos grupos escultóricos en orfebrería, probablemente, el Lignum Crucis de la catedral hispalense está muy próximo al relicario de San Simeón, en el tesoro de la catedral de

\footnotetext{
33 Ver entre otros: Ros, F. de, «Le Planctus Mariae du Pseudo-Anselme a Suso et a Louis de Grenade». Extrait de Mélanges Marcel Viller. Revue d'Ascetique et de Mystique, 99-100, 1949, 1-14.

Grano, G., «Planctus Mariae: analisi e sviluppo di una forma prototeatrale», Rivista italiana di drammaturgia, 18, 1980, 7-63.

${ }^{34}$ Castro, E., Teatro Medieval. El Drama Litúrgico, Barcelona, 1997, 233.

${ }^{35}$ Gauthier, M. M., Les Routes de la foi. Reliques et reliquaires de Jerusalem à Compostelle, Fribourg, $1983,154$.

Heredia, C., Orfebreria de Navarra, Edad Media. Pamplona 1986, 29.

${ }^{36}$ Clario di Fabio, «Oreficeria e smalti in Liguria», Annali della Scuola Normale Superiore di Pisa, XXI, 1, 1991, 247250. Situa el grupo del Museo de la Catderal de Savona en torno a 1400.

Gaborit-Chopin, D., «"La Fuite en Egypte” du Museo del Tesoro della Cattedrale de Savona et l'orfevrerie gothique française», en Tessuti, Oreficerie, Miniature in Liguria XIII- XV secolo. Bordiguera 1999, 81-102. Relaciona ambos grupos aproximandolos a talleres franceses, probablemente parisinos, de en torno a 1300.
} 
Aix la Chapelle (Fig. 7). Adornado con piedras y esmaltes, sus figuras de aspecto algo rígido se inscriben en el mismo contexto. Se sitúa en el segundo cuarto del siglo XIV, hacia 1330, fruto de talleres de orfebrería del Norte de Francia y de la región de Aix la Chapelle. Añade a pesar de algunas torpezas en el tratamiento, la idea de movimiento en el gesto de Simeón tomando al Niño y en el de la Virgen ofreciendo las palomas ${ }^{37}$. La obra de Sevilla, por la concepción del grupo y la expresividad de sus figuras, probablemente es algo más tardía, si bien recoge influencias de la orfebrería anterior. El tratamiento de los paños y los plegados finos que confieren a las figuras a veces una cierta inmaterialidad está en la tradición de obras mosanas del siglo xIII, como las estatuillas en la cruz relicario de la Vera Cruz del Tesoro de San Marcos de Venecia, la arqueta de St. Maurus (1220) para la abadía de Florennes, etc., pudiendo retrotraerse hasta Nicolás de Verdun en obras como la arqueta de Notre Dame de Tournai. Todo lleva a plantear que su realización ofrece notables comparaciones con obras nacidas en los talleres del Norte de Francia, sin olvidar el arte de corte cuya área de influencia desde Paris llega a Inglaterra y Alemania.

Muy interesante resulta la adición de los camafeos que, por expreso deseo del arzobispo, se incorporan a la cruz. Su empleo muestra que D. Pedro participó de una corriente, muy significativa en la época, de gusto por las obras antiguas. Como es sobradamente conocido, en numerosas piezas de orfebrería medieval, se asocian a los esmaltes, piedras preciosas, labor de repujado y filigrana, etc. entalles y camafeos. A veces proceden de la misma región donde han sido coleccionadas y, en ocasiones, de joyas de otros lugares que se transmiten de generación en generación y se reaprovechan ${ }^{38}$. Esta práctica cobra especial auge a mitad del siglo xIV en las cortes de Avignon, Praga y Paris, sin duda, gracias al gusto personal de Clemente VI, y en particular de Carlos IV y Carlos V. Ellos sienten gran predilección por estas muestras del mundo clásico, constituyendo una especie de homenaje al tiempo pasado que ejercía una extraña fascinación.

Clemente VI había conseguido de Felipe VI en 1343 el gran camafeo de la Chapelle que Carlos pudo recuperar y donar a la Sainte Chapelle en 1379. Sin embargo, fueron los soberanos quienes llegaron a reunir una colección excepcional. El emperador probablemente adquirió esta afición durante su estancia en Paris, donde comenzó a reunir una colección que fue ampliándose con obras que sus emisarios traían de diversos lugares, incluida Italia. Los inventarios del tesoro de la catedral de Saint Guy mencionan varios cientos de camafeos antiguos o bizantinos. Algunos los reutilizó en cruces, relicarios e incluso en la tumba de San Venceslao. En la clave de la bóveda de su oratorio en Karlstein montó uno galo-romano, excepcional, con una cabeza de Medusa. Esta pasión se sabe que le llevó a mandar realizar nuevos sobre modelos antiguos ${ }^{39}$.

El Rey Carlos V participaba de esta afición reuniendo asimismo una magnífica colección. Ya antes de ascender al trono, manifestó su interés por la orfebrería. En 1352 estando enfermo en Montereau mando que el orfebre Pierre de Barres le llevase una carretada de joyas que quería mirar para distraerse. En 1356 durante la cautividad de su padre y con serios problemas financieros, su tío el emperador Carlos IV, tuvo que reprocharle el excesivo lujo de su equipaje. Su colección, que engloba colecciones anteriores, fue sin duda la más importante en número, riqueza y variedad y su interés por las formas de arte antiguo, entre ellas los camafeos, es evidente. En el inventario se censan varios objetos d'ancienne façon ${ }^{40}$.

Sin duda, la amplia formación del arzobispo y su conocimiento exterior le hacían partícipe de las corrientes y preferencias artísticas del momento como lo muestra este hecho y la posesión de una obra tan significativa de la orfebrería.

\footnotetext{
37 Erlande Brandenburg, A., Le Monde Gothique. La Conquête de l'Europe. 1260-1380. Paris 1987, 286

Exposition, L'Europe Gothique xile-xvie. Siecles. Paris, 1968, n1 446, 287, lám. 133.

${ }_{38}$ Balty, J. Ch., «Gemmes antiques de la châsse de Sainte Gertrude», en Un Trésor gothique. La Chàsse de Nivelles, Cologne-Paris, 1996, 113-116.

39 Erlande-Brandenburg, A., op. cit., 1987, 312

${ }^{40}$ Gaborit Chopin, D., «Orfevrerie et emaillerie» en Les Fastes du Gothique. Le siècle de Charles V, Paris 1981-82, $220-224$.
} 

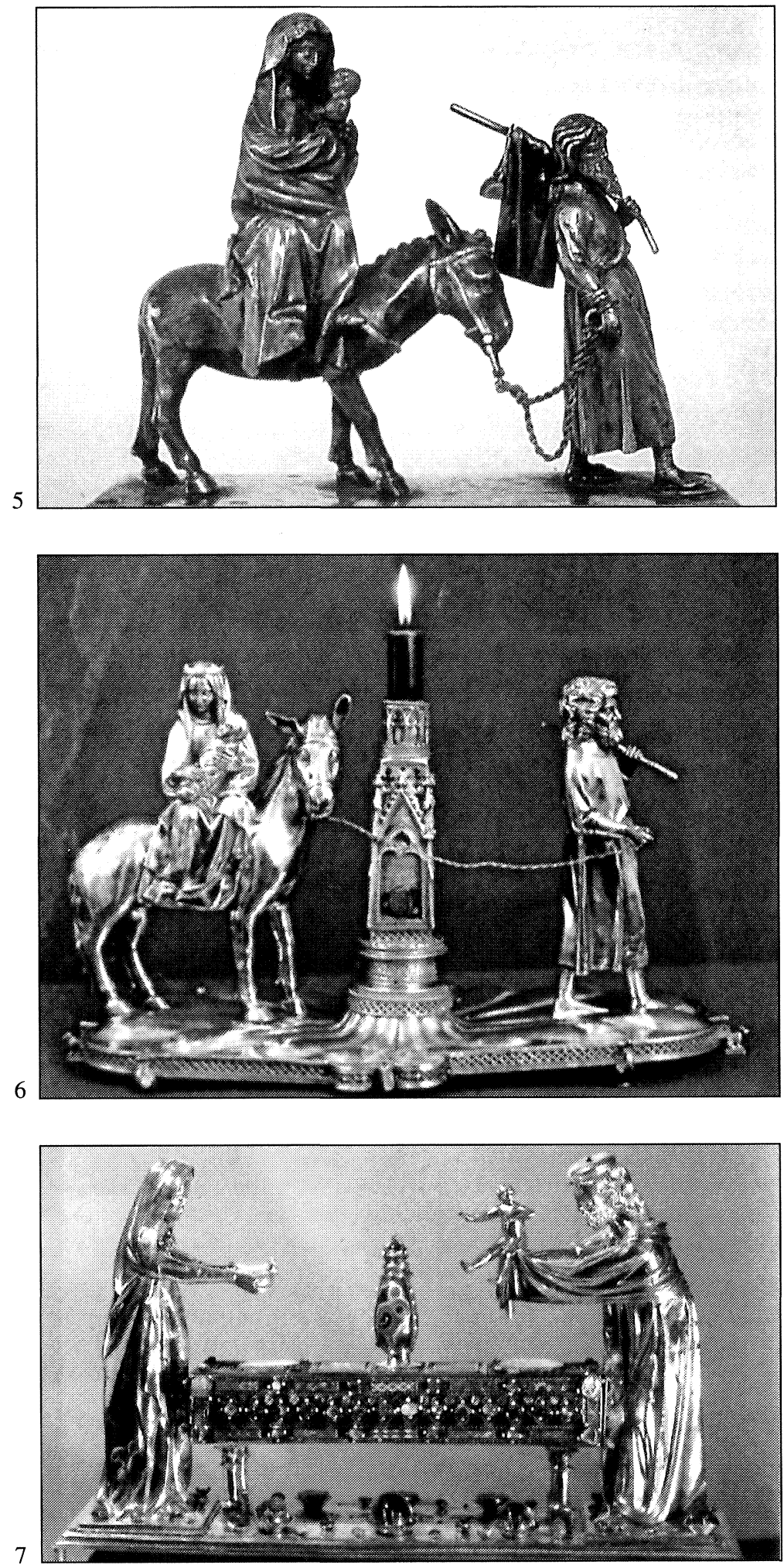

Fig. 5. Grupo de la Huida a Egipto. Museo de la Catedral de Savona.

Fig. 6. Grupo de la Huida a Egipto. Tesoro de la iglesia de SS. Anunziata, Gaeta.

Fig. 7. Relicario de S. Simeón. Tesoro de la catedral de Aix-la-Capelle.

$A E A, \mathrm{LXXVI}, 2003,301$, pp. 23 a 37 


\section{APÉNDICE}

Archivo Catedral Sevilla. Sec. Fondo Histórico General, C.117b N1 22/1. In nomine Domini Amen. Serie praesentis publici instrumenti cunctis pateat euidenter quod, anno a Natiuitate eiusdem Domini millesimo trecentesimo octuagesimo nono, indictione duodecima, die uero decima mensis iulii, pontificatus sanctissimi in Christo patris et // nomini nostri domini Clementis, diuina providentia, pape septimi anno undecimo in mei notarii publici et testium infrascriptorum ad hoc specialiter vocatorum et rogatorum praesentia reuerendissimus in Christo pater et dominus dominus Petrus, miseratione diuina // archiepiscopus Ispalensis affectans suam Ecclesiam Ispalensem donis merito honorare, sua bona premeditata sciencia et spontanea voluntate donatione, que dicitur inter viuos, dedit, donavit, cessit, mandauit, transtulit ac irrevocabiliter concessit dicte sue ecclesie et venerabilibus // et circumspectis viris dominis Petro Manuelis decano ipsius ecclesie, Iohanni Sancii Decretorum doctori de Xeritio Fernando Martinii de Mançiella, licenciato in Decretis de Nebula, archidiachonis in eadem Ecclesia, Didaco Martini, priori et porcionario eiusdem Ecclesie, // praesentibus et nomine dicte Ecclesie et Capituli Ispalensis recipientibus realiter tradidit et perpetuo transportauit bona sua infrascripta, videlicet unam crucem magnam auri in qua dixit esse quatuordecim marchas auri cum duabus marchis argenti paulo plus vel // minus cum nonnullis lapidibus preciosis cum suo pede crucis quasi quadrato de auro et cum quatuor ymaginibus etiam de auro una vidilicet christi et beate Marie et sancti Iohannis et beate Marie Magdalene et aliis duabus parvis Ymaginibus; est autem altitudo // ipsius crucis cum pede unius cubito vel circa. Item unum reliquiarium de argento deauratum cum suo pede deaurato esmaltato cum armis dicti domini archiepiscopi et superius in medio pedis cum duobus angelis et cum ymagine dicti domini archiepiscopi flexis // genibus existente et in capite ipsius reliquiarii cum una capsa cum suo coopertorio de beryllo ad modum cristalli cum suis orificiis de argento deauratis et cum uno ramo viridi desuper posito et uno pellicano cum suis filiis de argento deauratis. Item lapides // qui secuntur pro ornatu praedicte crucis videlicet quinque camafeos unum magnum et quatuor minores omnes sub figura capitis super calcedoniis et septem balayxos ponderis triginta et septem caractorum et duas esmeragdas unam modicam et alliam magnam // ponderis quinque caractorum cum dimidio et unum camafeum in quo est figura hominis habens campum nigrum parvum Ac duos alios lapides coloris balaxij unam cornalinam.Item quatuor lapides matistos. Item duos lapides topacios unum magnum // et alium minorem. Item tres peridones?. Item sex saphiros de talla ponderis sexaginta caractorum. Item sex saphyros perforatos et duos non perforatos ponderis septuaginta duorum caractorum. Item unum balaxium ponderis sex caractorum. Item quatuor dupplex // coloratos. Item unam gugunciam?. Item sexdecim lapides contrafactos diversorum colorum. Item libros sequentes primo vidilicet unum librum ....... omni vero alienatione eorumdem crucis reliquiarii lapidum et librorum penitus interdicta etiam quacumque neccesitate vel racione urgente volens mandans et ordinans que de donis ipsius domini archiepiscopi et suae mense // archiepiscopalis persolvantur expensae que adhuc restant fieri ad perficendum crucem et relicarium praedictum............

Signum Ego Guillemus Dodi de Sancto Vincentio, clericus diocesis Ebredunensis, publicus apostolica et imperiali auctoritatibus notarius, quia premissis omnibus et singulis dum sic, ut premittitur, agerentur et fierent vna // cum prenominatis testibus presens interfui et sic fieri vidi et audiui et dictam stipulationem feci, ideo de mandato prefati domini archiepiscopi ordinaui in notam recepit et publicauit et inde aliis occu // patus negotiis presens publicum instrumentum per alium fideliter scribi feci ipsumque hic mei manu mea propria subscribendo in hanc publicam formam redegi a signo meo consueto signaui per predictos // dominos decanum, archidiaconos et priorem etiam rogatus et requisitus in testimonium veritatis, approbans hic dictiones post lapsum in vltima linea cum signo positis superius in XIII linea post // dictionem hominis collocandas non vicio sed errore scriptoris omissas, item de dictione aliis superius in XXXO secunda linea in raso posita et non noceant quia approbo. Agradezco su trascripción al Prof. A.Chacón.

Este documento ha sido parcialmente transcrito en su comienzo, la relación de libros y el final por ÁLVAREZ MÁRQUEZ, C. Manuscritos localizados de Pedro Gómez Barroso y Juan de Cervantes, Arzobispos de Sevilla, Universidad de Alcalá, Excma. Diputación Provincial de Sevilla, 1999, 23-25. Por ello sólo transcribimos lo que atañe a nuestro estudio así como el final pues creemos interesante destacar las circunstancias de la donación.

Titulo delas reliquias $q$ (ue) estan enla sacristia $n . .^{\circ}$ pr(imer) Biblioteca Capitular y Colombina. Sevilla A.C.S. Secc. Fábrica. Lib. 397, fol. 2r-2v.

Primeramente una cruz de oro con su pie de oro/ con çinco figuras de ymagines de bulto de oro La . una de N(uest)ro Redemptor Jesu Christo quando lo ponen / en los braços de N(uest)ra Señora deçindiendolo de la Cruz / e Sant Joan e Joseph abarimatia e N(uest)ra Señora. El / pie es sexauado guarneçido cada sesauo de su creste / ria que tienen los quatro cada nueue Cresticas y / otro ocho y otro siete y en los huecos destos sesauos / estan seis ystorias esmaltadas todas de la Resurre / ction y un sesauo en que esta una historia de la

AEA, LXXVI, 2003, 301, pp. 23 a 37 
Re / surrection esta desemaltado y fortaleçido con plata / y en cada una dellas un escudo con una cruz en campo / colorado por armas que son las armas del señor arço / bispo don pedro que dio esta cruz y ençima del pie tie / ne por Reçebimiento donde asientan las ymagines / otros seis sesauos con su guarniçion de hojas todo de / oro y seis pieças esmaltadas de ymagines. Sobre esto / asienta una tabla de oro donde estan asentadas las / çinco ymagines y nasçe la cruz tallada de sus hojas / de Romano e debaxo del Jesu esta una planchita de / plata por sauana. En los tres braços desta cruz por / feneçimiento el de ençima tiene dos camafeos engas / tados el uno blanco y el otro blanco y leonado con dos / çafies engastados a los lados en dos florezitas en el / braço derecho de la cruz otros dos camafeos blancos / engastados y a los lados dos piedras engastadas en dos / florezitas La una es balaxe e la otra topazio en el / braço yzquierdo estan otros dos camafeos engasta / dos el uno es un niño blanco y el otro es un zostro / blanco e leonado y en los lados tiene engastadas / otras dos piedras en dos florezitas que son çafies / y en la delantera desta cruz desde los pies del Jesu / fasta el feneçimiento de los lados. E arriba ay / veinte y seis piedras engastadas de las quales son / las honze çafies e seis dellos grandes son / doce balaxes una grisolica un topacio una esme / ralda en el braço derecho de la misma hazera muy rica / asi que se cumplen las veinte y seis piedras deste / lado destas veinte y seis piedras de la faz faltan / dos la una tiene su vasico de oro en que ponerse / y la otra le falta el vasico. Con un bastilico(?) y en las / espaldas desta cruz ay otras veinte y seis piedras / que son las seis çafies las tres grandes diez balaxes / los tres (...) algo grandes quatro topazios y el uno que / esta en el pie es grande cinco esmeraldas y una griso / lica $q($ ue) todas son finas. Estas piedras delas espaldas / son veinte y çinco porque falta una piedra a un vasico / de oro. Esta cruz es toda de oro puro exçepto un pe / daçito q(ue) esta adobado e clavado en un pie sesauo de / la delantera. E la dicha Sauana tiene en medio un / tornillo de plata que se puede abrir y cerrar. Tiene / en los braços desta cruz en lo hueco unos viriles en / que ay dentro Reliquias encorporadas del Lignu(m) / crucis E de otros Diuersos Sanctos. Diola el Señor / arçobispo don pedro que sea en gloria esta en una / caxa de cuero esta quebrado un pedaçito de un viril / pesa quinze marcos y seis onças y una ochaua. 